CrossMark \& click for updates

Cite this: Mol. BioSyst., 2015, 11, 1622

Received 9th January 2015, Accepted 13th March 2015

DOI: $10.1039 / \mathrm{c} 5 \mathrm{mb} 00018 \mathrm{a}$

www.rsc.org/molecularbiosystems

\section{Comparative proteomic analysis of two distinct stem-cell populations from human amniotic fluid $\dagger$}

\author{
Rita Romani, ${ }^{\star a}$ Francesca Fallarino, ${ }^{a}$ Irene Pirisinu, ${ }^{a}$ Mario Calvitti, ${ }^{a}$ Anna Caselli, ${ }^{b}$ \\ Tania Fiaschi, ${ }^{\mathrm{b}}$ Tania Gamberi, ${ }^{\mathrm{b}}$ Davide Matino, ${ }^{\mathrm{a}}$ Vincenzo N. Talesa, ${ }^{\mathrm{a}}$ Emilio Donti, ${ }^{a}$ \\ Paolo Puccetti, ${ }^{a}$ Alessandra Modesti ${ }^{b}$ and Francesca Magherini ${ }^{b}$
}

\begin{abstract}
Human amniotic fluid (AF) contains a variety of stem cells of embryonic and extra-embryonic origins. We characterized two distinct types of stem cells isolated from residual AF material derived from prenatal diagnostic amniocentesis. The two types of cells differed in their morphology and growth kinetics, showing fast (fast human amniotic stem cells; fHASCs) or slow (slow human amniotic stem cells; sHASCs) population-doubling times. Both fHASCs and sHASCs expressed pluripotent stem-cell markers, yet unlike sHASCs, clonogenic fHASCs would generate embryoid bodies and maintain their original phenotype during prolonged in vitro passaging. fHASCs - but not sHASCs - expressed the KLF4, SSEA-4 and CD117 markers. Differential proteomic analysis allowed us to identify the protein patterns specific for either cell type as potentially contributing to their distinct phenotypes. We found thirty-six proteins that were differentially expressed by the two cell types, and those proteins were classified according to their biological and molecular functions. Bioinformatic cluster analysis revealed differential occurrence of cytoskeletal proteins, such as vimentin, F-actin-binding protein, and chloride intracellular channel protein 1. Selected proteins differentially expressed by fHASCs and sHASCs were further characterized by Western blot analysis and confocal microscopy.
\end{abstract}

\section{Introduction}

Human amniotic fluid (AF) derived from amniocentesis contains a variety of stem cells originating from embryonic and extra-embryonic tissues. Cells from the three embryonic layers (mesoderm, endoderm and ectoderm) have been found in AF, including epithelial-like cells, amniotic and trophoblast cells which produce estrogen and chorionic gonadotropin - and mesenchymal fibroblast cells. ${ }^{1,2}$ Several studies detected distinct cell progenitors in AF at early to late embryonic stages. ${ }^{3,4}$ Other studies reported the isolation of two main types of $\mathrm{AF}$ stem cell populations, namely, mesenchymal stem cells $\left(\right.$ AFMSCs) ${ }^{5,6}$ and amniotic-fluid stem cells (AFSCs). ${ }^{3}$ AFMSCs show the typical characteristics of mesenchymal stem cells (MSCs). ${ }^{6,7}$ In contrast, AFSCs are pluripotent ${ }^{7-9}$ and have intermediate characteristics between human embryonic stem cells (ESCs) and adult stem cells (ASCs). ${ }^{10}$

\footnotetext{
${ }^{a}$ Department of Experimental Medicine, University of Perugia, Polo Didattico Sant'Andrea delle Fratte, Piazzale Gambuli, 06132 Perugia, Italy. E-mail: rita.romani@unipg.it; Fax: +39-075-5858415; Tel: +39-075-5858356

${ }^{b}$ Department of Experimental and Clinical Biomedical Sciences "Mario Serio", University of Florence, Viale Morgagni 50, Florence, Italy.

E-mail: francesca.magherini@unifi.it; Tel: +39-055-2751237

$\dagger$ Electronic supplementary information (ESI) available. See DOI: 10.1039/ c5mb00018a
}

A limited number of studies have compared different AF stem cells by proteomic analysis. A two-dimensional proteomic database of AF-derived stem cells was first published by Roubelakis et al. in $2007 .{ }^{11}$ The study compared the protein expression of AF cells with that of bone-marrow mesenchymal stem cells. Although this study used a pool of heterogeneous cell populations with potentially different proliferation and metabolic profiles, the overall protein expression pattern of cells from either source was similar, suggesting that AF may represent an additional source of mesenchymal stem cells for both basic research and therapeutic applications. However, cultured AF stem cells also displayed a number of unique proteins involved in proliferation and associated with a primitive phenotype, likely accounting for the higher proliferation rates and enhanced adhesion properties of cultured AF cells relative to their bonemarrow counterparts. In 2011, a study reported by Roubelakis et al. described the characterization of two morphologically distinct AF mesenchymal progenitor cell-types. ${ }^{5}$ Although both populations expressed the typical markers of mesenchymal stem cells, they differed in shape, proliferation ability, and expression of the CD90 marker. Proteomic analysis of those two AF cell lines revealed twenty-five proteins that were differentially expressed as well as ten proteins unique to a single cell type.

We have previously reported the isolation of fast-growing human amniotic fluid stem cells (fHASCs), with characteristics 


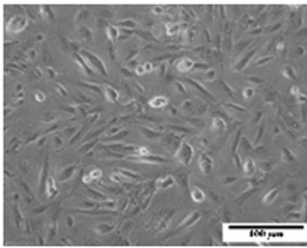

A

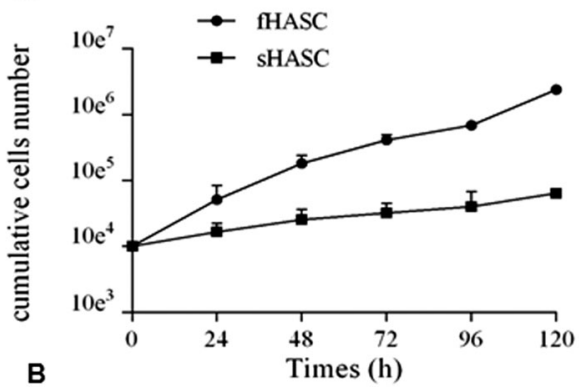

Fig. 1 HASC subpopulations exhibit distinct morphology and growth rates in vitro. Phase-contrast images of sHASCs and fHASCs at the sixth passage ( $\times 20$ magnification). (A) sHASCs with oval-shape morphology and fHASCs with fibroblast-like morphology. (B) Growth curves of HASC subsets. HASCs at fifth passage were seeded $\left(10^{4}\right.$ cells per well), and counted daily for five days. Mean values \pm SD of three independent samples from five different lines belonging to each population are shown.

common to ESCs and MSCs and characterized by potent immunomodulatory properties. ${ }^{12}$ Expanding upon those previous observations, we describe here the isolation and characterization of a second type of HASC that we termed slow-growing HASCs (sHASCs), owing to their poor proliferative capacity. Here we also describe the characteristics of these two cell types by a proteomic approach. Comparative analysis of the two types of HASCs - which do derive from the same source - clarifies the basic biological features underlying their distinct patterns of functionality, as well as to define the contribution of specific markers and proteins to either cell type phenotype. We found that fHASCs and sHASCs differed in their morphology, doubling times, expression of KLF4, SSEA-4 and CD117, clonogenicity, as well as in their capability to maintain the original phenotype during prolonged in vitro passaging. The proteomic analysis identified thirty-six spots differentially expressed by the two cell types that were further identified by mass spectrometry. Bioinformatic analysis revealed a significant involvement of cytoskeletal proteins, such as vimentin, F-actinbinding protein and chloride intracellular channel protein 1.

\section{Results and discussion}

\section{Isolation and characterization of HASCs}

We have previously described the isolation of AF stem-cell lines, referred to as fHASCs, that are characterized by a high rate of duplication in vitro, high differentiation ability and potent immunoregulatory properties. ${ }^{12}$ By using that procedure, as described in the previous paper, ${ }^{12}$ we report here the isolation of a second type of human amniotic stem cell that designated as slow-growing cells (sHASCs); they mostly differed from fHASCs in morphology and doubling times. Indeed, sHASCs were characterized by an oval-shaped morphology, as opposed to the fibroblast-like morphology of fHASCs (Fig. 1A). The two different cell types also showed different doubling times, namely, $14.0 \pm 0.43 \mathrm{~h}$ for fHASCs and $35.5 \pm 3.58 \mathrm{~h}$ for sHASCs (Fig. 1B). Furthermore, fHASCs could be cultured in vitro for more than two hundred generations, whereas sHASCs consistently failed to exceed thirty generations. Only fHASCs could be cryopreserved for prolonged periods of time, so as to allow the maintenance of their proliferative properties. Overall, of 1500 samples examined over time, about $60 \%$ gave rise to sHASCs and $40 \%$ to fHASCs.

In order to better characterize the two HASC lines, we evaluated the expression of the main markers expressed by stromal cells and the presence of stage-specific embryonic antigen (SSEA)-3 and SSEA-4. Both HASC lines expressed similar levels of the main stromal stem cell markers (Fig. 2). Moreover, both HASC types were characterized by the expression of high levels of stage-specific embryonic antigen (SSEA)-3, with SSEA-4 being more expressed in fHASCs (Fig. 3A). We also evaluated the expression of the main transcription factors associated with the maintenance of an undifferentiated phenotype and with pluripotency in ESCs, such as OCT-4A (POU class 5 homeobox, octamer-binding protein 4), NANOG, SOX2 sex-determining region Y (SRY)-box 2, c-MYC, FGF-4
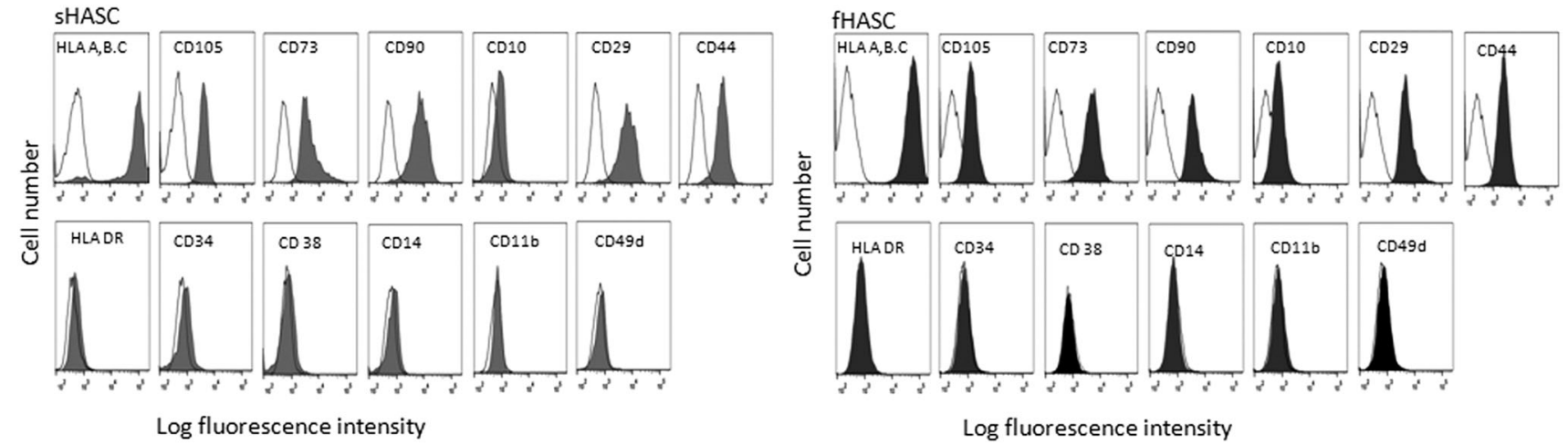

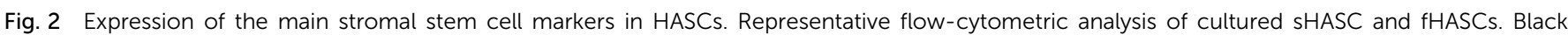
histograms indicate staining with an isotype-matched mouse IgG control antibody for sHASCs and fHASCs. 
A
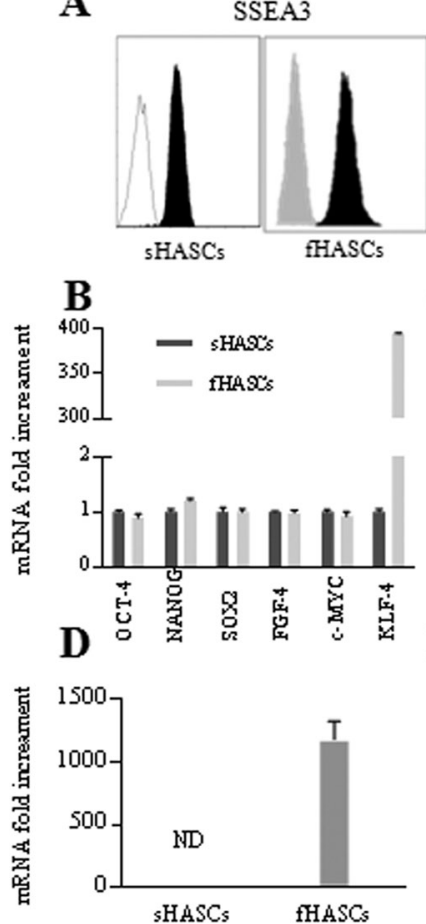

SSEA4

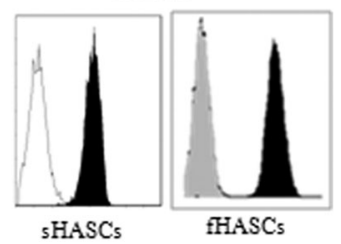

C
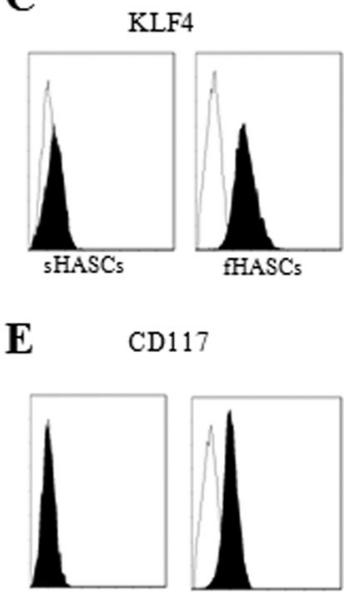

sHASCs

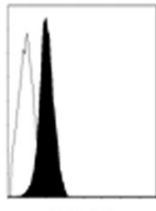

fHASCs

Fig. 3 Stem cell-like phenotype of sHASCs and fHASCs. (A) Analysis of the embryonic stem cell markers SSEA-3 and SSEA-4 by flow-cytometry. (B) Comparative analysis of pluripotent marker expression by real-time PCR (compiled data from three experiments, involving five samples of each cell type per experiment; ${ }^{\star \star} P<0.001$ ). (C) KLF4 protein expression in HASCs (D-E) CD117 expression was evaluated by real-time PCR and flowcytometry. Data are representative of three independent experiments performed on five SHASC and five fHASC lines. Shown are mean values $\pm \mathrm{SD}$ of three independent experiments (ND, not detectable).

(fibroblast growth factor 4), and KLF4 (gut-associated KruppelLike Factor 4) ${ }^{13-15}$ Comparative analysis of mRNA expression for the main transcription factors in both HASC lines showed that all those markers - except KLF4 - were equally expressed in fHASCs and sHASCs (Fig. 3B). Specifically, KLF4 expression in fHASC lines was 400 -fold higher than that in sHASCs and these results were confirmed by protein expression analysis (Fig. 3B and C). Differential expression of KLF4 might explain the disparate replicative abilities, because KLF4 plays an important role in the maintenance of self-renewal capacity in ESCs.

Because one widely used means of isolating AF stem cells relies on c-kit (CD117)-based immunoselection, we examined c-kit (CD117) expression in our HASC lines. We found that fHASCs, but not sHASCs, expressed CD117 intracellularly, (Fig. 3D and E). Several procedures can be used to characterize pluripotency in stem cells, including their ability to form embryoid bodies (EB), to differentiate into specific cell lineages, and to express pluripotency markers such as OCT-4, NANOG, and SOX2. ${ }^{16,17}$ We found that only fHASCs were able to generate EBs (Fig. 4), although both HASCs expressed OCT-4, NANOG, and SOX2 to the same extent (Fig. 2B). Moreover, analyzing the differentiation capability of the two cell types, we

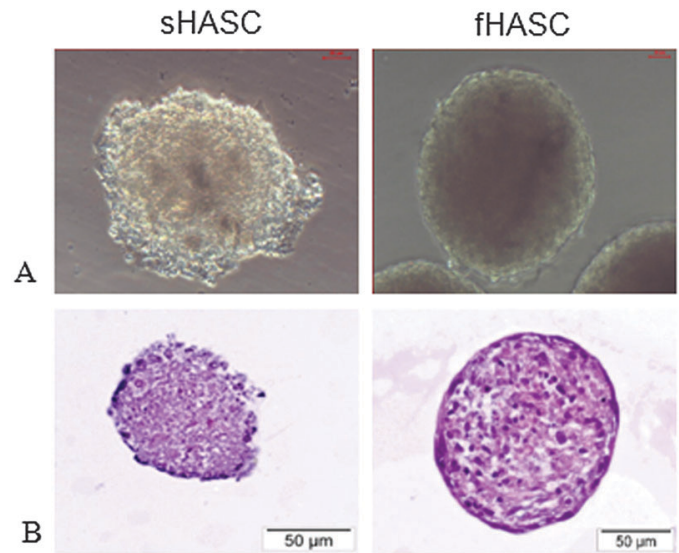

Fig. 4 Formation of embryoid bodies by HASCs. Representative pictures of embryoid bodies (EBs) formed by HASCs in hanging-drop cultures. (A) Morphology of EBs by sHASC and fHASC. (B) EBs stained with hematoxylin/eosin. EB images were obtained by phase-contrast microscopy ( $\times 20$ magnification).

found that, much like fHASCs, sHASCs would differentiate into specific mesodermal cell types, such as adipocytes and osteocytes (Fig. 5A). These data were confirmed by expression of specific adipogenic or osteogenic differentiation markers in both cell lines (Fig. 5B).

We also tested the ability of sHASCs to be cloned by serial dilution in vitro. Unlike fHASCs, sHASCs could not be cloned under the specific conditions used for fHASCs. ${ }^{12}$ Similar to our results, Roubelakis MG et al. isolated two types of AF stem cells that differed in their morphology, proliferative potential and expression of CD90, OCT-4, SOX2 and NANOG. ${ }^{5}$ The differences between the two types of stem cells found in that study are only partially similar with the two types of HASCs we have been characterizing. Whereas distinct proliferative potentials were found in both studies, our current study failed to detect differences in CD90, OCT-4, SOX2, and NANOG expressions between fHASCs and sHASCs, although the two types of AF cells did differ in their respective expressions of KLF4, CD117, and SSEA4 (Fig. 2 and 3).

\section{Proteomic analysis of HASCs}

Protein expression profiles of fHASCs and sHASCs were investigated by 2 -DE based proteomics. In particular, we selected 5 lines referable to fHASCs and 4 lines referable to sHASCs. Each line was run in triplicate on 2-D gels; protein spots were visualized by silver staining. The 2-DE gel images were analyzed using Progenesis SameSpots software 4.0 (Nonlinear Dynamics, UK) with default parameters. After automatic spot detection an average of about 2600 protein spots was detected in each gel. Computational analysis revealed 50 differentially expressed protein spots with an ANOVA $P$ value $\leq 0.05$ (Fig. 6). Moreover, we calculated the power of our statistical analysis. In our experiments, we achieved a target power of $87 \%$ confirming that the number of sample replicates used was appropriate. 

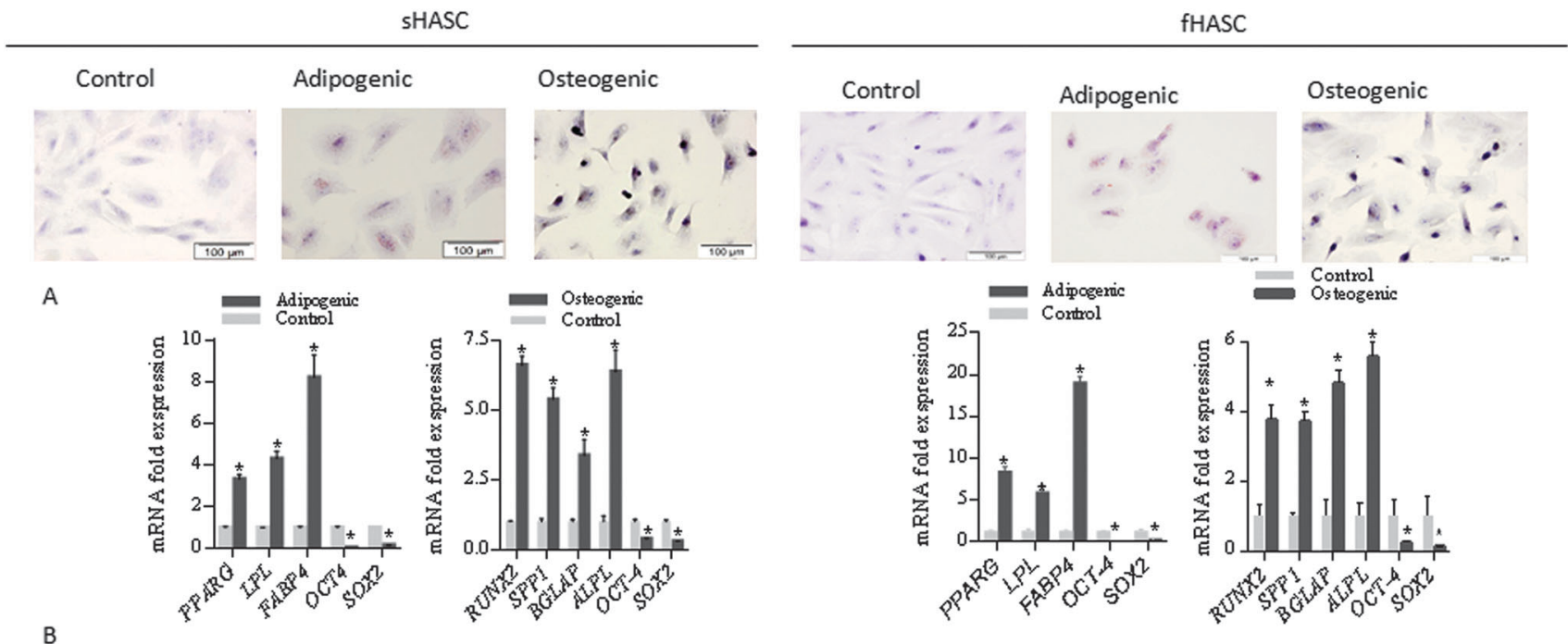

Fig. 5 Differentiation potential of HASCs. (A) Representative pictures of sHASC and fHASC differentiation into adipocytes and osteocytes, respectively. Differentiation was monitored by Sudan III staining and von Kossa staining, respectively; nuclear staining with Mayer's hematoxylin. (B) The RT-PCR analysis of mRNA levels of specific adipogenic (PPARG, LPL, FABP4) and osteogenic (RUNX2, SPP1, BGLAP, ALPL) markers for sHASCs or fHASCs. Analysis was performed at day 21 of differentiation as compared to day 0 , which corresponds to fold change $=1$. Data are representative of three independent experiments performed on five sHASC and five fHASC lines $\left({ }^{*} P<0.05\right)$
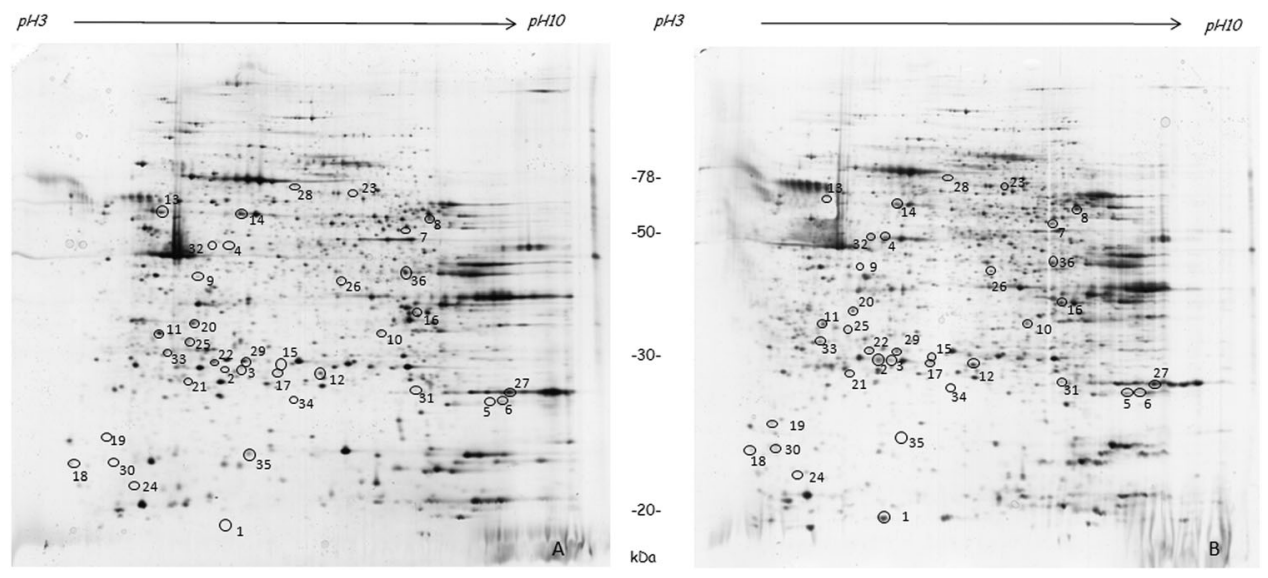

Fig. 6 Representative silver-stained 2-D gels of fHASCs (A) and sHASCs (B). Proteins (40 g) were separated by their pl on 3-10 non-linear IPG strips $(18 \mathrm{~cm})$ and by their molecular weight on $9-16 \%$ polyacrylamide linear gradient gels. Black circles and numbers indicate spots that presented a differential expression and were identified by mass spectrometry.

For mass spectrometry analysis, we selected those spots showing an increase of $\geq 1.5$ fold and spots were manually picked from preparative colloidal Coomassie blue silver-stained gels. Thirty-six spots were successfully identified and are reported in Fig. 6 and Table 2. The identification of Vimentin was also confirmed by MS/MS analysis (Fig. 1S, ESI $\dagger$ ). Proteins identified by mass spectrometry were functionally classified using the online resource PANTHER classification system (http://www. pantherdb.org/) (Fig. 7). According to the "molecular function" most of the proteins belong to "catalytic activity" (GO:0003824) (32.8\%), "binding" (GO:0005488) (29.3\%) and "structural molecule activity" (GO:0005198) (13.8\%), whilst according to the "biological process" most of the proteins belong to the metabolic process (GO:0008152) (27\%) and the "cellular process" (GO:0009987) (19\%).
To better understand the biological meaning of those proteins that were differentially expressed, we performed a statistical overrepresentation test. The results are reported in Table 3. $P$ values were corrected using Bonferroni correction for multiple testing and only the categories with a $P$ value $\leq 0.1$ were reported. The involvement of cytoskeletal proteins in the different characteristics of the two cell types becomes obvious on considering both the "molecular function" and "cellular component" categories. Belonging this group are Actin, F-actin capping protein, vimentin, BTB/POZ domaincontaining protein 1 , and chloride intracellular channel protein 1 . F-actin capping protein binds to the fast growing ends of actin filaments and plays a role in the regulation of cell morphology and cytoskeletal organization. Vimentins are class-III intermediate filaments found in various non-epithelial 

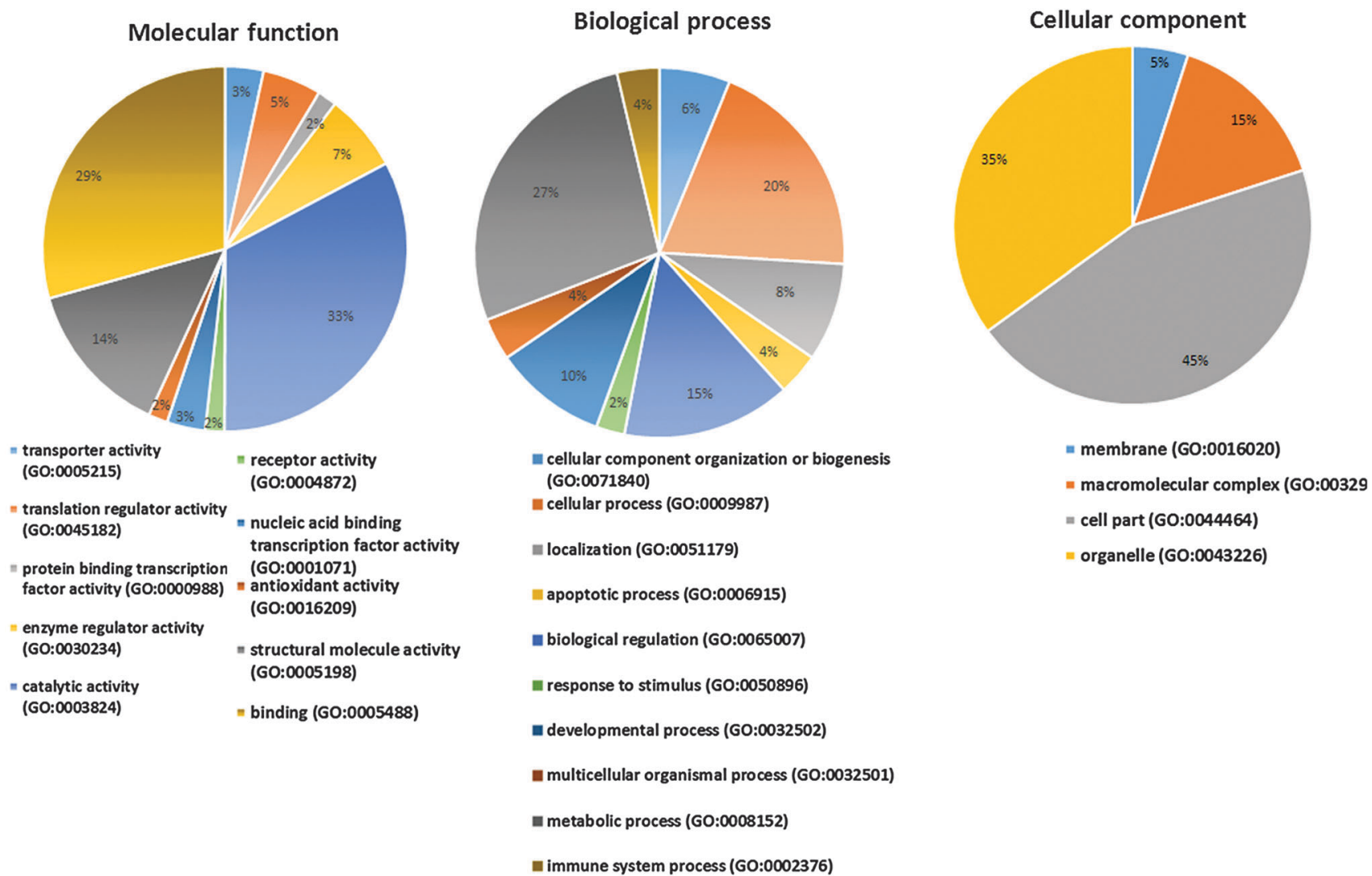

Fig. 7 Pie chart representations of the distribution of identified proteins according to their molecular functions, biological processes and cellular component. Categorizations were based on information provided using the online resource PANTHER classification system.

cells, especially mesenchymal cells. The different expression of these proteins could contribute to the different morphology associated with fast and slow HASCs. Interestingly, several studies describe a pivotal role of chloride intracellular channel protein in promoting cancer cell proliferation. ${ }^{18-20}$ This protein is more expressed in fHASCs than in sHASCs and could contribute to the high proliferation rate observed in this line.

\section{Validation of proteomics results}

Western blot analysis with specific antibodies was used to validate the expression changes of the Ser/thr-protein phosphatase PP1- $\gamma$ catalytic subunit, insulin-like growth factorbinding protein 3, IGFPB3 (found as a mix with bovine serum albumin and the glutamate-cysteine ligase regulatory subunit, respectively) and vimentin. The results are reported in Fig. 8A and confirm the proteomic findings. Vimentin and IGFBP3 were more expressed in fHASCs whilst PP1- $\gamma$ was more expressed in sHASCs. Furthermore, for IGFBP3, we performed 2D-GE followed by Western blot. In fact, the spot corresponding to this protein was detected at an experimentally measured pI of 6.0, whereas its theoretical pI is 9.0. This shift was confirmed also by western blot as shown in Fig. 8B. In particular, antibodies against IGFPB3 detected this protein in two spots: one located at a pI around 6 (corresponding to the identified spot) and the other located around pI 9. In both cases, the signal was clearly higher in fHASCs compared to sHASCs. Failure of the computer-aided analysis of the gels to reveal differences in the spots at pI 9 could be explained by the fact that, in this area of the gels, spots were not well resolved, and thus the image analysis program was unable to find statistically significant differences.

PP1- $\gamma$ and IGFBP3 are proteins involved in several regulatory pathways of cell growth and metabolism. PP1- $\gamma$ figures prominently in a wide range of cellular processes, including meiosis and cell division, apoptosis, protein synthesis, glycogen metabolism, cytoskeletal reorganization, and regulation of membrane receptors and channels. ${ }^{21}$ IGFBP3 is a multifunctional protein found both in circulation and inside the cells. It regulates cell proliferation and apoptosis in insulin-like growth factor (IGF)dependent and independent manners. ${ }^{22}$ Several studies indicate that IGFBP3 enhances growth and other cell functions depending on specific conditions. ${ }^{23,24}$ Vimentin differential expression was also confirmed by confocal microscopy that showed both a lower expression and a lower level of filament organization in sHASCs than in fHASCs (Fig. 8C). Vimentin is a member of the type III intermediate filaments and is a marker of cells of mesenchymal origin. Vimentin filaments are involved in motility, maintenance of cell shape and endurance of mechanical stress of mesenchymal cells. ${ }^{25}$ The oval-shape of sHASCs could be partially explained by the lack of vimentin in cytoskeletal organization. 


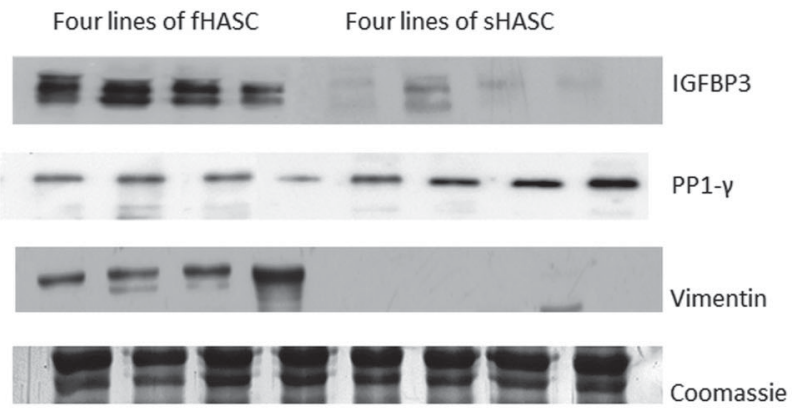

A

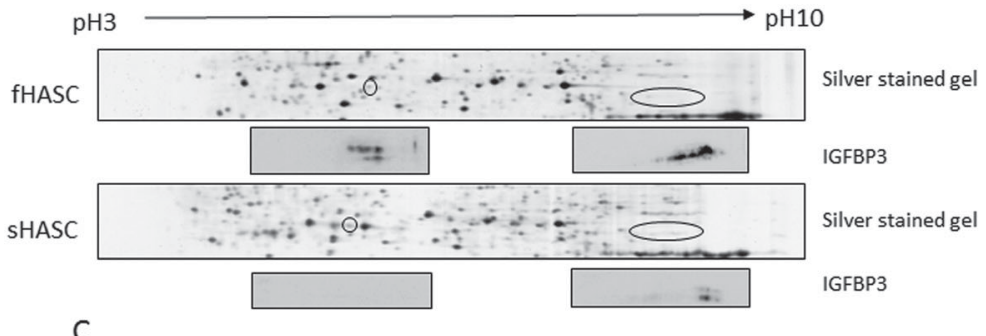

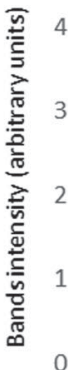
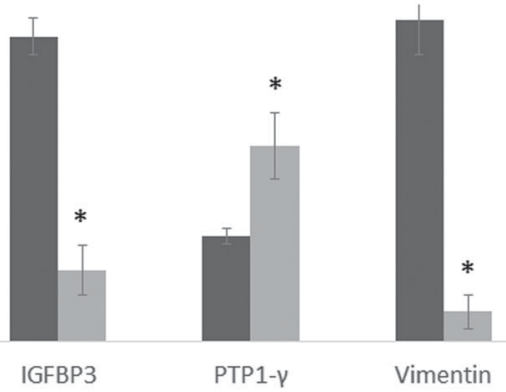

B
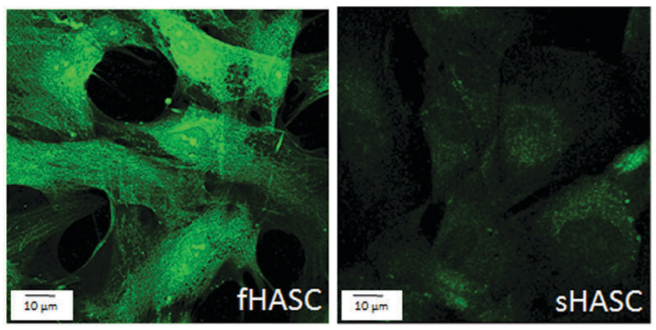

D

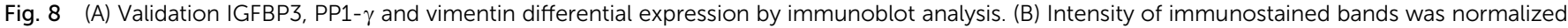

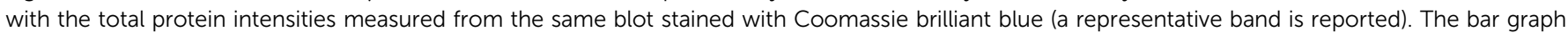

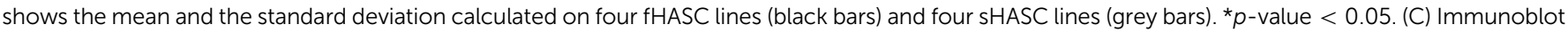

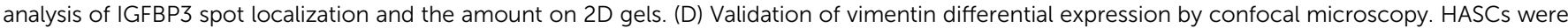

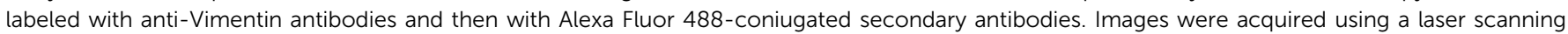
confocal microscope (Leica TCS SP5).

\section{Conclusions}

Human amniotic fluid, which can be obtained during routine amniocentesis with no major ethical concerns, is considered an important source of different types of stem cells. The characterization of these cells is very important for their possible application in regenerative medicine and tissue repair.

Here we demonstrate that two types of HASCs can be isolated from human AF. Although the two types of HASCs express similar levels of many pluripotency markers, they differ in morphology, differentiation ability and proliferative capacity. Both HASCs show similar expressions of the main stromal stem-cell markers and transcription factors associated with the maintenance of an undifferentiated state and with pluripotency in ESCs, except for KLF4. Both HASC types are able to differentiate into adipocytes and osteocytes. Proteomic analysis of these lines pointed out some interesting findings. In fact, although 2-DE based proteomic studies cannot assess the alterations registered in the expression of all the genes in the genome, they offer a chance to identify post-transcriptional modifications that can be involved in the control of the expression programs of stem cell populations. In this context, we found that IGFBP3 is not only more expressed in fHASCs, but it is also detected in some isoforms not present in sHASCs. The other intriguing point is the different expression profile of several cytoskeletal proteins that could be involved in the different morphology shown by the two lines. In conclusion, in the present study, we found that HASCs differ in specific phenotype features (e.g., morphology, doubling times, and differentiation potential) as well as in the expression of several proteins. Differences in specific protein expressions in the distinct HASC populations were limited, and this finding could be due to the fact that they share a common origin. Those proteins nevertheless are of particular interest because of their involvement in functions such as control of proliferation (Klf4, CD117, IGFBP3) and morphology (vimentin and F-actin capping protein). Additional studies will be meant to provide further insight into the roles of those proteins in determining disparate phenotypes among functionally distinct HASC populations.

\section{Experimental}

\section{HASC isolation and culture}

HASCs were obtained from human amniotic fluids of 16-17week pregnant women (aged 35-40 years), who underwent amniocentesis during routine prenatal diagnosis. The study was approved by the University of Perugia Bioethics Committee, and each participant provided informed consent for the secondary use of amniotic fluid samples. The procedure for isolation of stem cells was according to the study reported by Romani et al. ${ }^{12}$ Briefly, an aliquot (3-5 ml) of fresh amniotic fluid or residual cells from prenatal diagnosis tests was cultured in mesenchymal stem cell growth medium (MSCGM and 
Table 1 Real-time PCR primer sequences

\begin{tabular}{|c|c|c|c|}
\hline NANOG & NM_024865 & $5^{\prime}{\text { CCACCAGTCCCAAAGGCAAAC }{ }^{\prime}}^{\prime}$ & 5'GAGGTTCAGGATGTTGGAGAGTTC3' \\
\hline FGF-4 & NM_002007 & 5'GGCGTGGTGAGCATCTTC3' & 5'GTAGGCGTTGTAGTTGTTGG3' \\
\hline c-MYC & NM_002467 & 5'GCGTCCTGGGAAGGGAGATCCGGAGC3' & $5^{\prime}$ TTGAGGGGCATCGTCGCGGGAGGCTG3' \\
\hline KLF4 & NM_004235 & 5'ACGGCTGTGGATGGAAATTC $3^{\prime}$ & 5'ATGTGTAAGGCGAGGTGGTC3' \\
\hline SPP1 & NM_001251830 & 5'GCAGGAGGAGGCAGAGCACAG3' & 5'GGTCGGCGTTTGGCTGAGAAGG3' \\
\hline PPARG & NM_015869 & 5'GGTTGACACAGAGATGCCATTC3' & 5'TGGAGTAGAAATGCTGGAGAAGTC3' \\
\hline LPL & NM_000237 & 5'CCGTGTGGCTCCAGAGTC3 ${ }^{\prime}$ & 5'GAATGAGGTGGCAAGTGTCC3' \\
\hline FABP4 & NM_001442 & 5'AGAAGTAGGAGTGGGCTTTGC3' & 5'ATCTAAGGTTATGGTGCTCTTGAC3' \\
\hline АСТВ & NM_001101 & 5'СTCTTCCAGCCTTCСТTCСТ $3^{\prime}$ & 5'AGCACTGTGTTGGCGTACAG3' \\
\hline
\end{tabular}

LONZA); the isolation consisted of selecting the cultures containing cells with peculiar morphology and colony shape. These colonies were then selected and cultured for several passages in vitro.

\section{Cell growth curves, determination of the doubling time,} cloning assay, and cryopreservation

HASCs were trypsinized at the fifth passage and plated at $10^{4}$ cells per well (in 12 -well plates), in triplicate, and in the presence of MSCGM media. Cells were trypsinized and counted daily for 5 days. The HASC population-doubling time (TD) was calculated using the formula, TD $=t \times \log _{2} / \log \left(N_{t} / N_{0}\right)$, where $N_{0}$ is the inoculum cell number and $N_{t}$ is the cell harvest number at time $t .^{26}$ Three independent experiments were performed, each in triplicate. To determine any clonogenic capacity, HASCs were cloned by limiting dilution. The HASC clones were expanded for ten passages and subsequently evaluated for their immunophenotype and expression of pluripotency markers. Aliquots of $1 \times 10^{6}$ cells were stored in cryovials at $-80{ }^{\circ} \mathrm{C}$ for 3 days, and then in liquid nitrogen. The cryoprotectant solution consisted of MSCGM with 50\% ES-FBS and 10\% DMSO (Sigma-Aldrich).

\section{Flow cytometry}

Phenotypical characterization of HASCs was performed as follows. Staining and analysis with FITC- or PE-conjugated antibodies were performed according to standard protocols, on an EPICS flow cytometer, by the use of EXPO 32 ADC software (Beckman Coulter). For HASC surface antigen analysis, cells were harvested by trypsinization, washed with phosphatebuffered saline, supplemented with FBS (3\%) and stained with antibodies to the following-HLA A,B,C (Beckton Dickinson); class II DR, CD10, CD11b, CD14, CD29, CD34, CD38, CD44, CD49d, CD73, and CD105 (Immunotools); CD90, CD117 (c-kit), SSEA3, SSEA4, and OCT4 (Biolegend). To detect intracellular markers, cells were permeabilized with $0.2 \%$ (vol/vol) Triton-X (Sigma-Aldrich) for $30 \mathrm{~min}$ at room temperature before staining.

\section{RT-PCR analysis}

Total RNA was extracted from HASCs by Trizol (Invitrogen) and used as a template for reverse transcription to cDNA. cDNA was obtained using the RevertAid First Strand cDNA Synthesis Kit
(Fermentas); mRNA quantitation was performed by RT-PCR analyses using Brilliant SYBR Green QPCR Master Mix 2x (Stratagene) with the Mx3000P qPCR System (Stratagene). The reaction was performed following the manufacturer's recommendations. Each sample was normalized to $\beta$-actin (Invitrogen). The final results, expressed as relative expressions, were calculated using MxPro software (Stratagene). Each experiment was repeated at least three times for all cell lines at different passages. The $2^{-\Delta \Delta C T}$ method was applied as a comparative method of quantitation, and data were normalized to $\beta$-actin RNA expression. Primers sequences are shown in Table 1.

\section{Embryoid body, osteogenic and adipogenic differentiation}

Embryoid body (EB) formation was assessed by the method described by Valli A. et al. ${ }^{27}$ To induce osteogenic differentiation, HASCs, harvested at passage 5 and with $60-70 \%$ confluency, were cultured in Differentiation Media BulletKitsOsteogenic (LONZA), according to manufacturer's instructions. The differentiation potential for osteogenesis was assessed by mineralization of calcium accumulation on von Kossa staining (Abcam), according to producer's instructions; moreover, we determined changes in RT-PCR expression of specific genes, namely, Secreted Phospho-Protein 1 (SPP1), Bone Gammacarboxyglutamate (Gla) Protein (BGLAP), Runt-related transcription factor 2 (RUNX2), Alkaline Phosphatase, and Liver/ bone/kidney (ALPL). To induce adipogenic differentiation, HASCs harvested as indicated above were cultured in Differentiation Media BulletKits-Adipogenic (LONZA). The potential for adipogenic differentiation was assessed by Sudan III staining (Sigma-Aldrich), according to the manufacturer's instructions. The changes in the expression of specific genes, markers of adipogenic differentiation, such as Peroxisome Proliferator-Activated Receptor Gamma (PPARG), Lipo-Protein Lipase (LPL), and Fatty Acid Binding Protein 4 (FABP4), were also determined by RT-PCR.

\section{Sample preparation and 2-D gel electrophoresis}

Cells were scraped in RIPA buffer (50 mM Tris-HCl, pH 7.0, 1\% NP-40, $150 \mathrm{mM}$ NaCl, 2 mM EGTA, $100 \mathrm{mM} \mathrm{NaF}$ ) containing a cocktail of protease inhibitors (Sigma). After centrifugation, proteins were precipitated following a chloroform-methanol protocol $^{28}$ and suspended in $8 \mathrm{M}$ urea, 4\% (w/v) and $20 \mathrm{mMDTT}$. 
Table 2 Differentially expressed proteins identified by 2-DE coupled with MALDI-TOF MS analysis

\begin{tabular}{|c|c|c|c|c|c|c|c|c|c|}
\hline \multirow[b]{2}{*}{$\begin{array}{l}\text { Spot } \\
\text { number }\end{array}$} & \multirow[b]{2}{*}{$\begin{array}{l}\text { Accession } \\
\text { No }\end{array}$} & \multirow[b]{2}{*}{ Protein name } & \multicolumn{3}{|c|}{ MASCOT search results } & \multirow[b]{2}{*}{$\begin{array}{l}\text { Measured } \\
\mathrm{pI} / M_{\mathrm{r}}(\mathrm{kDa})\end{array}$} & \multirow[b]{2}{*}{$\begin{array}{l}\text { Theoretical } \\
\mathrm{pI} / M_{\mathrm{r}}(\mathrm{kDa})\end{array}$} & \multirow[b]{2}{*}{$\begin{array}{l}\text { Fold change } \\
\text { fast } v s \text {. slow }{ }^{d}\end{array}$} & \multirow[b]{2}{*}{$\begin{array}{l}\text { ANOVA }^{e} \\
(p \text { value })\end{array}$} \\
\hline & & & $\begin{array}{l}\text { No. of } \\
\text { matched } \\
\text { peptides }^{a}\end{array}$ & $\begin{array}{l}\text { Sequence } \\
\text { coverage }^{b} \\
(\%)\end{array}$ & Score $^{c}$ & & & & \\
\hline 1 & P55854 & Small ubiquitin-related modifier 3 & 4 & 26 & 58 & $5.4 / 10$ & $5.3 / 12$ & -4.8 & $2.6 \times 10^{-6}$ \\
\hline 2 & Q9H3R5 & Centromere protein $\mathrm{H}$ & 11 & 48 & 143 & $5.3 / 26$ & $5.2 / 28$ & -1.7 & 0.002 \\
\hline \multirow[t]{2}{*}{$3 \operatorname{mix}$} & P17936 & $\begin{array}{l}\text { Insulin-like growth factor-binding } \\
\text { protein } 3\end{array}$ & 6 & 35 & 85 & $6.0 / 27$ & $9.0 / 33$ & 2.5 & $1.06 \times 10^{-5}$ \\
\hline & P48507 & $\begin{array}{l}\text { Glutamate-cysteine ligase } \\
\text { regulatory subunit }\end{array}$ & 7 & 21 & 90 & $6.0 / 27$ & $5.7 / 31$ & & \\
\hline \multirow[t]{2}{*}{4 mix } & P36873 & $\begin{array}{l}\text { Ser/thr-protein phosphatase PP1- } \gamma \\
\text { catalytic subunit }\end{array}$ & 10 & 32 & 107 & $5.5 / 43$ & $6.1 / 38$ & -2.2 & $1.16 \times 10^{-5}$ \\
\hline & P02769 & $\begin{array}{l}\text { Bovine serum albumin precursor } \\
\text { (264-607 fragment) }\end{array}$ & 18 & 71 & $274^{a}$ & $5.6 / 66$ & $5.3 / 39$ & & \\
\hline 5 & P37802 & Transgelin-2 & 11 & 51 & 158 & $8.2 / 22$ & $8.4 / 23$ & -3.4 & $7.7 \times 10^{-6}$ \\
\hline 6 & P37802 & Transgelin-2 & 12 & 62 & 171 & $8.8 / 22$ & $8.4 / 23$ & -2.9 & $5.7 \times 10^{-6}$ \\
\hline 7 & P13639 & $\begin{array}{l}\text { Elongation factor } 2 \text { ( } 439-858 \\
\text { fragment) }\end{array}$ & 16 & 22 & $158^{a}$ & $7.5 / 53$ & $6.4 / 96$ & -1.8 & 0.003 \\
\hline 8 & P14618 & Pyruvate kinase PKM & 15 & 36 & 164 & $7.7 / 62$ & $8.0 / 58$ & -1.8 & $8.8 \times 10^{-6}$ \\
\hline \multirow[t]{2}{*}{$9 \operatorname{mix}$} & O75031 & Heat shock factor 2-binding protein & 11 & 38 & 99 & $5.2 / 38$ & $5.4 / 38$ & 3.6 & $6.6 \times 10^{-6}$ \\
\hline & P35237 & Serpin B6 & 13 & 40 & 116 & $5.2 / 38$ & $5.2 / 43$ & & \\
\hline 10 & Q96PM5 & $\begin{array}{l}\text { RING finger and CHY zinc finger } \\
\text { domain-containing protein } 1\end{array}$ & 8 & 34 & 78 & $7.2 / 31$ & $6.3 / 32$ & -1.9 & $7.9 \times 10^{-6}$ \\
\hline 11 & O00299 & $\begin{array}{l}\text { Chloride intracellular channel } \\
\text { protein } 1\end{array}$ & 14 & 80 & 214 & $5.1 / 31$ & $5.1 / 27$ & 1.8 & $1.4 \times 10^{-4}$ \\
\hline 12 & A6NDG6 & Phosphoglycolate phosphatase & 8 & 37 & 87 & $6.5 / 25$ & $5.9 / 34$ & -1.9 & $1.61 \times 10^{-4}$ \\
\hline 13 & $\mathrm{P} 08670$ & Vimentin & 37 & 72 & 368 & $5.1 / 66$ & $5.1 / 54$ & 2.5 & $2.62 \times 10^{-4}$ \\
\hline 14 & P48637 & Glutathione synthetase & 9 & 29 & 104 & $5.5 / 51$ & $5.7 / 525.2 / 47$ & 2 & $2.7 \times 10^{-4}$ \\
\hline 15 & Q96EQ8 & $\begin{array}{l}\text { E3 ubiquitin-protein ligase } \\
\text { RNF125 }\end{array}$ & 8 & 43 & 82 & $6.1 / 28$ & $6.7 / 27$ & -2 & $9.1 \times 10^{-4}$ \\
\hline 16 & P60891 & $\begin{array}{l}\text { Ribose-phosphate pyrophospho } \\
\text { kinase } 1\end{array}$ & 7 & 33 & 78 & $7.6 / 34$ & $6.5 / 35$ & -2.3 & 0.001 \\
\hline 17 & Q9UKA8 & Calcipressin-3 & 5 & 29 & 64 & $6.0 / 25$ & $4.5 / 28$ & -1.7 & 0.001 \\
\hline 18 & P05112 & Interleukin-4 & 8 & 53 & 96 & $4.9 / 18$ & $9.2 / 18$ & -2.6 & 0.002 \\
\hline 19 & O43752 & Syntaxin-6 & 7 & 32 & 89 & $5.0 / 20$ & $4.8 / 29$ & -3.5 & 0.002 \\
\hline 20 & Q9UJV9 & $\begin{array}{l}\text { Probable ATP-dependent RNA } \\
\text { helicase DDX } 41\end{array}$ & 10 & 21 & 64 & $5.2 / 33$ & $6.4 / 70$ & -1.6 & 0.002 \\
\hline 21 & Q9BY32 & $\begin{array}{l}\text { Inosine triphosphate } \\
\text { pyrophosphatase }\end{array}$ & 5 & 35 & 76 & $5.2 / 24$ & $5.5 / 22$ & 1.7 & 0.002 \\
\hline 22 & P47756 & $\begin{array}{l}\text { F-actin-capping protein subunit } \\
\text { beta }\end{array}$ & 5 & 29 & 60 & $5.3 / 29$ & $5.4 / 32$ & 1.7 & 0.002 \\
\hline \multirow[t]{2}{*}{$23 \operatorname{mix}$} & P81274 & G-protein-signaling modulator 2 & 10 & 22 & 68 & $6.9 / 83$ & $5.8 / 77$ & -1.9 & 0.003 \\
\hline & P81133 & Single-minded homolog 1 & 9 & 17 & 58 & $6.9 / 83$ & & & \\
\hline 25 & Q8NC06 & $\begin{array}{l}\text { Acyl-CoA-binding domain- } \\
\text { containing protein } 4\end{array}$ & 10 & 36 & 128 & $5.2 / 30$ & $6.8 / 31$ & 1.7 & 0.004 \\
\hline 26 & P00558 & Phosphoglycerate kinase 1 & 12 & 34 & 110 & $6.9 / 37$ & $8.3 / 45$ & -1.8 & 0.006 \\
\hline 27 & Q6ZN17 & Protein lin-28 homolog B & 6 & 28 & 61 & $8.0 / 26$ & $9.1 / 28$ & -1.8 & 0.004 \\
\hline 28 & Q96BJ8 & $\begin{array}{l}\text { Engulfment and cell motility } \\
\text { protein } 3\end{array}$ & 13 & 22 & 137 & $6.4 / 83$ & $5.9 / 82$ & 1.7 & 0.003 \\
\hline 29 & Q13162 & Peroxiredoxin-4 & 7 & 45 & 122 & $5.9 / 29$ & $5.9 / 31$ & 1.8 & 0.002 \\
\hline 30 & O00231 & $\begin{array}{l}26 \mathrm{~S} \text { proteasome non-ATPase } \\
\text { regulatory subunit } 11\end{array}$ & 6 & 17 & 55 & $5.0 / 17$ & $6.1 / 48$ & -4 & 0.004 \\
\hline 31 & P25705 & $\begin{array}{l}\text { ATP synthase subunit alpha } \\
\text { (300-553 fragment) }\end{array}$ & 7 & 47 & $94^{a}$ & $7.7 / 26$ & $8.0 / 28$ & -2.3 & $9.1 \times 10^{-4}$ \\
\hline 32 & P63261 & Actin, cytoplasmic 2 & 11 & 38 & 104 & $5.3 / 42$ & $5.3 / 41$ & -2.5 & $7.9 \times 10^{-5}$ \\
\hline 33 & P01036 & Cystatin-S & 5 & 56 & 80 & $4.9 / 16$ & $5.13 / 28$ & 1.9 & 0.002 \\
\hline 34 & P61221 & $\begin{array}{l}\text { ATP-binding cassette } \\
\text { sub-family E member } 1\end{array}$ & 14 & 20 & 138 & $8.6 / 67$ & $6.5 / 23$ & 2 & 0.002 \\
\hline 35 & Q9H0C5 & $\begin{array}{l}\mathrm{BTB} / \mathrm{POZ} \text { domain-containing } \\
\text { protein } 1\end{array}$ & 6 & 13 & 70 & $5.7 / 53$ & $5.9 / 19$ & 3.1 & 0.002 \\
\hline 36 & Q9BWF3 & RNA-binding protein 4 & 10 & 37 & 97 & $6.6 / 41$ & $4.1 / 40$ & -2 & $7.8 \times 10^{-4}$ \\
\hline
\end{tabular}

${ }^{a}$ Number of matched peptides corresponds to peptide masses matching the top hit from Ms-Fit PMF. ${ }^{b}$ Sequence coverage $=($ number of the identified residues/total number of amino acid residues in the protein sequence) $\times 100 \%{ }^{c}$ MASCOT MS score (Matrix Science, London, UK; http:// www.matrixscience.com). The MS matching score greater than 56 was required for a significant MS hit $(p$-value $<0.05) .{ }^{d}$ Fold change (fHASCs $v s$. sHASCs) was calculated dividing the average of $\% V$ fHASCs by the average of $\% V$ sHASCs. $(V=$ volume $=$ integration of the optical density over the spot area; $\% V=V$ single spot $/ V$ total spots included in the reference gel) using Progenesis SameSpots 4.0 software. ${ }^{e}$ Anova test was performed using Progenesis SameSpots 4.0 software to determine if the relative change was statistically significant $(p<0.05)$. 
Table 3 Statistical overrepresentation based on Panther ontology

\begin{tabular}{|c|c|c|c|c|}
\hline & $\begin{array}{l}\text { Homo sapiens } \\
\text { - REFLIST } \\
(21804)\end{array}$ & $\begin{array}{l}\text { Proteins } \\
\text { found }\end{array}$ & $\begin{array}{l}\text { Proteins } \\
\text { expected }\end{array}$ & ( $p$-value) \\
\hline \multicolumn{5}{|l|}{ Cellular component } \\
\hline Cytoskeleton & 786 & 7 & 1.30 & $1.34 \times 10^{-02}$ \\
\hline Intracellular & 1434 & 9 & 2.37 & $2.16 \times 10^{-02}$ \\
\hline Actin cytoskeleton & 388 & 5 & .64 & $2.17 \times 10^{-02}$ \\
\hline Cell part & 1592 & 9 & 2.63 & $4.61 \times 10^{-02}$ \\
\hline Organelle & 1051 & 7 & 1.74 & $7.48 \times 10^{-02}$ \\
\hline \multicolumn{5}{|l|}{ Molecular Function } \\
\hline Catalytic activity & 5529 & 19 & 9.13 & $6.21 \times 10^{-02}$ \\
\hline $\begin{array}{l}\text { Structural } \\
\text { Constituent of } \\
\text { cytoskeleton } \\
\text { Pathway }\end{array}$ & 851 & 7 & 1.41 & $6.70 \times 10^{-02}$ \\
\hline Glycolysis & 21 & 2 & 0.03 & $1.01 \times 10^{-01}$ \\
\hline
\end{tabular}

Two replicates were performed for each cell line. IEF (first dimension) was carried out on non-linear wide range immobilized $\mathrm{pH}$ gradients (pH 3.0-10; 18 cm long IPG strips; GE Healthcare, Uppsala, Sweden) and achieved using the Ettan ${ }^{\mathrm{TM}}$ IPGphor $^{\mathrm{TM}}$ system (GE Healthcare, Uppsala, Sweden). For the analytical-run purpose, IPG strips were rehydrated with $60 \mu \mathrm{g}$ of total proteins in $350 \mu \mathrm{L}$ of lysis buffer and $0.2 \%$ of carrier ampholyte for $1 \mathrm{~h}$ at $0 \mathrm{~V}$ and for $8 \mathrm{~h}$ at $30 \mathrm{~V}$, at $20{ }^{\circ} \mathrm{C}$. MS-preparative IPG strips were loaded with $600 \mu \mathrm{g}$ of proteins. The strips were focused at $20{ }^{\circ} \mathrm{C}$ according to the following electrical conditions: $200 \mathrm{~V}$ for $1 \mathrm{~h}$, from $300 \mathrm{~V}$ to $3500 \mathrm{~V}$ in $30 \mathrm{~min}, 3500 \mathrm{~V}$ for $3 \mathrm{~h}$, from $3500 \mathrm{~V}$ to $8000 \mathrm{~V}$ in $30 \mathrm{~min}$, and $8000 \mathrm{~V}$ until a total of $80000 \mathrm{~V} \mathrm{~h}^{-1}$ was reached. After focusing, analytical and preparative IPG strips were equilibrated for $12 \mathrm{~min}$ in $6 \mathrm{M}$ urea, $30 \%$ glycerol, 2\% SDS, 2\% DTT in $0.05 \mathrm{M}$ Tris-HCl buffer, $\mathrm{pH}$ 6.8, and subsequently for $5 \mathrm{~min}$ in the same urea-SDS-Tris buffer solution where DTT was substituted with $2.5 \%$ iodoacetamide. The second dimension was carried out on $9-16 \%$ polyacrylamide linear gradient gels $(18 \mathrm{~cm} \times 20 \mathrm{~cm} \times 1.5 \mathrm{~mm})$ at $10{ }^{\circ} \mathrm{C}$ and $40 \mathrm{~mA}$ per gel constant current until the dye front reached the bottom of the gel in a PROTEAN II xi cell gel electrophoresis unit (Bio-Rad). Analytical gels were stained with ammoniacal silver nitrate as previously described; ${ }^{29}$ MS-preparative gels were stained with colloidal Coomassie blue silver. ${ }^{30}$

\section{Image analysis and statistic}

Gel images were digitized using the Epson expression 1680 PRO scanner and saved with a resolution of $300 \mathrm{dpi}$ and as a 16-bit TIFF format. Computer aided 2D image analysis was carried out using Progenesis SameSpots software version 4.0 (Nonlinear Dynamics, UK) which allows spot detection, background subtraction and protein spot volume quantification. The gel image showing the highest number of spots and the best protein pattern was chosen as the reference image and its spots were then matched across all gels. Gels were manually corrected to remove wrongly assigned or duplicated spots and image artifacts. Gel to gel variation was checked by a routine procedure that controls the coefficient of variation $(\mathrm{CV})$. The average $\mathrm{CV}$ for all matched spots in our experimental series is less than $30 \%$, indicating a typical variability according to Molloy et $a l .{ }^{31}$ Relative spot volume $(\% V=V$ single spot $/ V$ total spots, where $V$ is the integration of the optical density over the spot area) was used during analysis in order to reduce the experimental error. The correlation coefficient of reproducibility of our gels was always higher than 0.89. The accepted power threshold is $\geq 0.8 .^{32}$ Statistical analysis was performed using default parameters of the Progenesis SameSpots Statmodule. The $\log _{10}$-normalized spot volume was used for the analysis as the $\log$ transformation improves normality. ${ }^{33}$ The univariate data analysis was performed as one-way ANOVA $(p<0.05)$ on each spot individually.

\section{In-gel digestion and MALDI-TOF analysis}

Protein spots, corresponding to differentially expressed proteins, were manually excised from Coomassie blue silver stained gels. Samples were washed in $50 \mathrm{mM}$ ammonium bicarbonate $\left(\mathrm{NH}_{4} \mathrm{HCO}_{3}\right) / \mathrm{CH}_{3} \mathrm{CN} 1 / 1$, reduced in $10 \mathrm{mM}$ DTT for 30 minutes at $56{ }^{\circ} \mathrm{C}$, carbamidomethylated with $55 \mathrm{mM}$ iodoacetamide for 30 minutes in the dark and incubated for 1 hour at $37{ }^{\circ} \mathrm{C}$ with $20 \mu \mathrm{L}$ of $20 \mu \mathrm{g} \mathrm{mL}{ }^{-1}$ trypsin solution (Trypsin Proteomics Sequencing Grade, Sigma) in $40 \mathrm{mM}$ $\mathrm{NH}_{4} \mathrm{HCO}_{3}$ with $10 \% \mathrm{CH}_{3} \mathrm{CN}$. An additional $30 \mu \mathrm{L}$ of $40 \mathrm{mM}$ $\mathrm{NH}_{4} \mathrm{HCO}_{3}$ with $10 \% \mathrm{CH}_{3} \mathrm{CN}$ were added to each sample and incubated overnight at $37{ }^{\circ} \mathrm{C}$. The reaction was stopped adding a final concentration of $0.1 \%$ trifluoroacetic acid. The supernatant was collected and the gel was further extracted with $0.1 \%$ trifluoracetic acid in $50 \% \mathrm{CH}_{3} \mathrm{CN}$. The extracts were combined. A $0.75 \mu \mathrm{L}$ volume of the sample was mixed to $0.75 \mu \mathrm{L}$ of the matrix (saturated solution of $\alpha$-cyano-4hydroxycinnamic acid in 50\% (v/v) $\mathrm{CH}_{3} \mathrm{CN}$ and $0.5 \%(\mathrm{v} / \mathrm{v})$ TFA) on the anchorchip target plate and allowed to dry. Protein identification was carried out by peptide mass fingerprinting (PMF) on an Ultraflex III MALDI-TOF/TOF mass spectrometer (Bruker Daltonics) equipped with a $200 \mathrm{~Hz}$ smartbeam $^{\mathrm{TM}}$ I laser by using Flex Control 3.0 as data acquisition software. Spectra were acquired in reflectron mode over the $\mathrm{m} / \mathrm{z}$ range $860-4000$ for a total of 500 shots. The instrumental parameters were chosen by setting the ion source 1 at $25 \mathrm{kV}$, ion source 2 at $21.5 \mathrm{kV}$, the pulsed ion extraction at $20 \mathrm{~ns}$ and the detector gain at $7.7 \times$. The instrument was externally calibrated prior to analysis using the Bruker Peptide Calibration standard kit. All the resulting mass lists were cleaned up from eventually present contaminant masses, such as those from the matrix, autodigestion of trypsin and keratins. Mass fingerprint searching was carried out in the UniProtKB database (http://www. uniprot.org/) using MASCOT v2.1 (Matrix Science Ltd, London, UK, http://www.matrixscience.com) software. The taxonomy was restricted to Homo sapiens, a mass tolerance of $100 \mathrm{ppm}$ was allowed, and the number of accepted missed cleavage sites was set to one. Alkylation of cysteine by carbamidomethylation was assumed as fixed modification. The experimental mass values were monoisotopic. No restrictions on protein molecular weight and pI were applied. The criteria used to accept identifications included the extent of sequence coverage, the number of matched peptides and the probabilistic score sorted using the software $(p<0.05)$. 


\section{Western blot analysis of proteomic candidates}

For 2D-GE and western blot, $50 \mu \mathrm{g}$ of protein extracts were separated on non-linear wide range immobilized $\mathrm{pH}$ gradients (pH 3.0-10; $11 \mathrm{~cm}$ long IPG strips; GE Healthcare, Uppsala, Sweden) and achieved using the $\operatorname{Ettan}^{\mathrm{TM}}$ IPGphor $^{\mathrm{TM}}$ system (GE Healthcare, Uppsala, Sweden). Focusing was performed at $20{ }^{\circ} \mathrm{C}$ according to the following electrical conditions: $200 \mathrm{~V}$ for $1 \mathrm{~h}$, from $300 \mathrm{~V}$ to $3500 \mathrm{~V}$ in $30 \mathrm{~min}, 3500 \mathrm{~V}$ for $3 \mathrm{~h}$, from $3500 \mathrm{~V}$ to $6000 \mathrm{~V}$ in $30 \mathrm{~min}$, and $6000 \mathrm{~V}$ until a total of $20000 \mathrm{~V} \mathrm{~h}^{-1}$ was reached. The strip was treated as described previously and the second dimension was performed on Criterion TGX gels (gradient 8-16\%, Biorad). For 1D-GE and western blot, $20 \mu \mathrm{g}$ of protein extracts were separated by $12 \%$ SDS-PAGE. In both cases gels were transferred onto a PVDF membrane (Millipore). The relative amount of Vimentin, PP1- $\gamma$ and IGFBP3 were assessed by Western blot with appropriate antibodies (Santa Cruz Biotechnology). The blots were subjected to densitometric analysis by using Quantity One Software (Bio-Rad). Subsequently these blots were stained with Coomassie brilliant blue R-250. For quantification, the intensity of the immunostained bands was normalized with the total protein intensities measured by Coomassie brilliant blue R-250 from the same blot. Statistical analysis of the data was performed by Student's $t$-test; $p$-values $<0.05$ were considered statistically significant.

\section{Confocal analysis}

Cells were seeded onto coverslips, and after 48 hours of washing with phosphate buffered saline, and fixed in 3\% paraformaldehyde for $20 \mathrm{~min}$ at $4{ }^{\circ} \mathrm{C}$. Fixed cells were permeabilized with three washes with $0.1 \%$ Triton X-100 (in $50 \mathrm{mM}$ Tris- $\mathrm{HCl}$, pH 7.4, $150 \mathrm{mM} \mathrm{NaCl}$ ) (TBST) and blocked with 5.5\% horse serum in TBST for $1 \mathrm{~h}$ at room temperature. Cells were incubated with vimentin primary antibodies overnight at $4{ }^{\circ} \mathrm{C}$. Cells were incubated with 488 Alexa Fluor-conjugated secondary antibodies (diluted $1: 100$ ) for $1 \mathrm{~h}$ at room temperature in TBST containing $3 \%$ bovine serum albumin. After extensive washes in TBST, cells were mounted with glycerol plastine and observed under a laser scanning confocal microscope (Leica TCS SP5).

\section{Notes}

Presented, in part, at the IX Annual Congress of Italian Proteomics Association held in Naples, 24th-27th June 2014.

\section{Authors' contributions}

FM conceived and designed the experiments, performed 2-DE gel image analysis, and wrote the manuscript; RR conceived and designed the experiments, performed isolation and characterization of stem cells, and wrote the manuscript; TG performed 2-DE gel image analysis and helped in drafting the manuscript; TF contributed in writing the manuscript; AC performed mass spectrometry analysis. ED and AM helped in drafting the manuscript. IP performed cell culture and RT-PCR experiments; FF conceived and designed the experiments, and performed cytofluorimetric experiments; DM performed experiments, and analyzed data. VNT and PP conceived and designed the experiments; MC performed histological staining experiments.

All authors read and approved the final manuscript.

\section{Acknowledgements}

This work was supported by the grant, Prot. No. 2012.0280.021 of the Fondazione Cassa di Risparmio di Perugia *(to RR and $\mathrm{FF}$ ), the Bayer Special Project Award (to FF) and the Italian Association for Cancer Research (AIRC, to P.P.). We thank G. Andrielli for digital art and image editing and F. Fabi for technical assistance.

\section{References}

1 H. Hoehn and D. Salk, Methods Cell Biol., 1982, 26, 11.

2 C. M. Gosden, Br. Biomed. Bull., 1983, 39, 348.

3 P. De Coppi, G. Bartsch, M. M. Siddiqui, T. Xu, C. C. Santos, L. Perin, G. Mostoslavsky, A. C. Serre, E. Y. Snyder, J. J. Yoo, M. E. Furth, S. Soker and A. Atala, Nat. Biotechnol., 2007, $25,100$.

4 S. M. Kunisaki, M. Armant, G. S. Kao, K. Stevenson, H. Kim and D. O. Fauza, Journal of Pediatric Surgery, 2007, 42, 974.

5 M. G. Roubelakis, V. Bitsika, D. Zagoura, O. Trohatou, K. I. Pappa, M. Makridakis, A. Antsaklis, A. Vlahou and N. P. Anagnou, J. Cell. Mol. Med., 2011, 15, 1896.

6 M. S. Tsai, S. M. Hwang, Y. L. Tsai, F. C. Cheng, J. L. Lee and Y. J. Chang, Biol. Reprod., 2006, 74, 545.

7 M. Cananzi, A. Atala and P. De Coppi, Reprod. BioMed. Online, 2009, 18, 17.

8 S. Bajada, I. Mazakova, J. B. Richardson and N. Ashammakhi, J. Tissue Eng. Regener. Med., 2008, 2, 169.

9 N. Siegel, M. Rosner, M. Hanneder, A. Valli and M. Hengstschlager, Stem Cell Rev., 2007, 3, 256.

10 A. Trounson, Nat. Biotechnol., 2007, 25, 62.

11 M. G. Roubelakis, K. I. Pappa, V. Bitsika, D. Zagoura, A. Vlahou, H. A. Papadaki, A. Antsaklis and N. P. Anagnou, Stem Cells Dev., 2007, 16, 931.

12 R. Romani, I. Pirisinu, M. Calvitti, M. T. Pallotta, M. Gargaro, G. Bistoni, C. Vaccaa, A. Di Michele, C. Orabona, J. Rosati, M. Pirro, S. Giovagnoli, D. Matino, P. Prontera, G. Rosia, U. Grohmanna, V. N. Talesa, E. Donti, P. Puccetti and F. Fallarino, J. Cell. Mol. Med., DOI: 10.1111/jcmm.12534.

13 P. Y. Bourillot and P. Savatier, Bmc Biol., 2010, 8.

14 L. A. Boyer, T. I. Lee, M. F. Cole, S. E. Johnstone, S. S. Levine, J. R. Zucker, M. G. Guenther, R. M. Kumar, H. L. Murray, R. G. Jenner, D. K. Gifford, D. A. Melton, R. Jaenisch and R. A. Young, Cell, 2005, 122, 947.

15 S. H. Orkin, J. Wang, J. Kim, J. Chu, S. Rao, X. Shen and D. Levasseur, FEBS J., 2008, 275, 53. 
16 C. Buta, R. David, R. Dressel, M. Emgard, C. Fuchs, U. Gross, L. Healy, J. Hescheler, R. Kolar, U. Martin, H. Mikkers, F. J. Muller, R. K. Schneider, A. E. M. Seiler, H. Spielmann and G. Weitzer, Stem Cell Res., 2013, 11, 552.

17 M. Marti, L. Mulero, C. Pardo, C. Morera, M. Carrio, L. Laricchia-Robbio, C. R. Esteban and J. C. I. Belmonte, Nat. Protoc., 2013, 8, 223.

18 Y. D. Tian, Y. B. Guan, Y. Y. Jia, Q. J. Meng and J. J. Yang, Cancer Biother.Radiopharm., 2014, 29, 339.

19 L. Wang, S. M. He, Y. Y. Tu, P. G. Ji, J. H. Zong, J. Y. Zhang, F. Q. Feng, J. P. Zhao, Y. S. Zhang and G. D. Gao, J. Exp. Clin. Cancer Res., 2012, 31, 44.

20 P. Wang, C. Zhang, P. W. Yu, B. Tang, T. Liu, H. Cui and J. H. Xu, Mol. Cell. Biochem., 2012, 365, 313.

21 H. Ceulemans and M. Bollen, Physiol. Rev., 2004, 84, 1.

22 S. Jogie-Brahim, D. Feldman and Y. Oh Y, Endocr. Rev., 2009, 30, 417.

23 K. H. Chang, T. Chan-Ling, E. L. McFarland, A. Afzal, H. Pan, L. C. Baxter, L. C. Shaw, S. Caballero, N. Sengupta, S. Li Calzi, S. M. Sullivan and M. B. Grant, Proc. Natl. Acad. Sci. U. S. A., 2007, 104, 10595.
24 R. Granata, L. Trovato, G. Garbarino, M. Taliano, R. Ponti, G. Sala, R. Ghidoni and E. Ghigo, FASEB J., 2004, 18, 1456.

25 E. J. Clarke and V. Allan, Curr. Biol., 2002, 12, R596.

26 Q. You, X. Tong, Y. Guan, D. Zhang, M. Huang, Y. Zhang and J. Zheng, J. Int. Med. Res., 2009, 37, 105.

27 A. Valli, M. Rosner, C. Fuchs, N. Siegel, C. E. Bishop, H. Dolznig, U. Madel, W. Feichtinger, A. Atala and M. Hengstschlager, Oncogene, 2010, 29, 966.

28 D. Wessel and A. Flügge, Anal. Biochem., 1984, 138, 141.

29 D. F. Hochstrasser, A. Patchornik and C. R. Merril, Anal. Biochem., 1988, 173, 412.

30 G. Candiano, M. Bruschi, L. Musante, L. Santucci, G. M. Ghiggeri, B. Carnemolla, P. Orecchia, L. Zardi and P. G. Righetti, Electrophoresis, 2004, 25, 1327.

31 M. P. Molloy, E. E. Brzezinski, J. Q. Hang, M. T. McDowell and R. A. VanBogelen, Proteomics, 2003, 3, 1912.

32 S. M. N. Hunt, M. R. Thomas, L. T. Sebastian, S. K. Pedersen, R. L. Harcourt, A. J. Sloane and M. R. Wilkins, J. Proteome Res., 2005, 4, 809.

33 N. A. Karp, M. Spencer, H. Lindsay, K. O'Dell and K. S. Lilley, J. Proteome Res., 2005, 4, 1867. 